\title{
PROUNISTAS QUE INGRESSAM NA PÓS-GRADUAÇÃO
}

\author{
PROUNI STUDENTS WHO ENROLLED IN GRADUATE STUDIES
}

\author{
ALUMNOS PROUNISTAS QUE INGRESARON EN EL POSTGRADO
}

\section{Maria Teresa Cauduro ${ }^{1}$ Flávia Obino Corrêa Werle ${ }^{2}$}

\begin{abstract}
RESUMO: O artigo apresenta os resultados de uma pesquisa com estudo de caso na região do Alto Uruguai e das Missões, em específico, no Programa de Pós-graduação em Educação da Universidade Regional Integrada do Alto Uruguai e das Missões (PPGEDU-URI/FW). A pesquisa, realizada em 2013, buscou investigar o perfil dos acadêmicos ex-prounistas da URI/FW que ingressaram na pós-graduação em Educação no período de 2011 a 2013 e o impacto da política pública para eles. O estudo caracterizou-se como uma pesquisa quantitativa de caráter descritivo e com estudo de caso, que teve por finalidade registrar e analisar fenômenos fundamentados nas ideias de Bourdieu como capital cultural. A amostra deste estudo se constituiu de forma não probabilística e intencional por oito mestrandos ex-prounistas que ingressaram no Programa de Mestrado em Educação no período mencionado. A amostra do estudo compõe a totalidade da população de ex-prounistas que ingressaram no Programa de Mestrado. A tabulação dos dados foi manual e utilizou-se da estatística descritiva (frequência e percentagem), por meio do emprego do programa Microsoft Excel. Como conclusão, os resultados foram que $100 \%$ dos investigados registraram que sem o ProUni não teriam tido condições de ingressar no Ensino Superior; que, ao concluir a graduação, em seguida foram absorvidos pelo mercado, possibilitando geração de renda. Não contentes, buscaram outro nível de diploma (outro investimento) para terem acesso à melhoria de posição social e remuneração. Sugere-se que esses dados sirvam para ampliar outras investigações com dados mais quantitativos e qualitativos.
\end{abstract}

PALAVRAS-CHAVE: ProUni. Políticas Públicas. Programas de Pós-Graduação.

ABSTRACT: The paper presents the results of a case study research conducted in the Rio Grande do Sul state's region called Alto UruguaieMissões, involving the Department of Education of the Universidade Regional Integradado Alto Uruguai e das Missões (URI/FW). This research, carried out in 2013, sought to analyze the profile of URI/FW former PROUNI students who enrolled in graduate studies in the field of Education from 2011 to 2013 and the impact of this public policy on them. As a qualitative study, with descriptive features and a study case, it sought to document and analyze some phenomena grounded on Bourdieu's ideas as cultural capital. The sample of this study consisted of eight former PROUNI graduate students who enrolled in the Master's Program of Education in the mentioned period. This sample compounds the totality of former PROUNI students who enrolled in the Master's Program. The tabulation of data was done manually and used descriptive statistics (frequency and percentage) through Microsoft Excel. As a result, we see that 100 percent of the students involved said that without PROUNI they would not have means to access Higher Education training, and that, when finishing their ungraduated courses, they were soon absorbed by the market enabling income generation. Not content with what they had achieved, these students sought another degree (another investment) to have access to a better social status and remuneration. We suggest these data be used to expand further investigations with more quantitative and qualitative data.

\footnotetext{
${ }^{1}$ Doutorado em Filosofia e Ciências da Educação pela Universidade de Barcelona, Espanha (1999). Pesquisadora convidada da Universidade do Vale do Rio dos Sinos, Brasil. E-mail: maitecauduro@gmail.com.

${ }^{2}$ Doutorado em Educação pela Pontifícia Universidade Católica do Rio Grande do Sul (1993). Professora titular da Universidade do Vale do Rio dos Sinos, Brasil. E-mail: flaviaw2008@gmail.com.

Recebido em: 06/07/2015 - Aprovado em: 09/11/2015.
}

\begin{tabular}{l|l|l|l|l|l|l|} 
(C) ETD -Educ. Temat. Digit. & Campinas, SP & v.17 & n.3 & p. 596-613 & set./dez.2015 & ISSN $1676-2592$
\end{tabular}


KEYWORDS: ProUni. Public policy. Graduate programs.

RESUMEN: El artículo presenta los resultados de una investigación a partir de unestudio de caso enlaregióndel Alto Uruguay y de lasMisiones, en particular enel Programa de PosgradoenEducación de la Universidad Regional Integrada de Alto Uruguay y de lasMisiones (PPGEDU-URI / FW). La encuesta, realizada en 2013, trató de investigar el perfil delexalumnosprounistas de la URI / FW que entróenelpostgrado de educaciónenel período 2011-2013 y el impacto de las políticas públicas para ellos. El estudio se caracteriza por ser unestudiocuantitativo, descriptivo e tenía como objetivo registrar y analizar fenómenos basados enlasideas de Bourdieu como capital cultural. La muestra de este estudioconsistióen forma no probabilística e intencional por ochoex alumnosprounistas que entraronenel Programa de Master enEducaciónenel período mencionado. La muestradelestudiocomprende a toda lapoblación de exprounistas que entraronenel Programa. La tabulación de losdatosfue manual y utiliza la estadística descriptiva (frecuencia y porcentaje) a través del uso del programa Microsoft Excel. Enconclusión, los resultados fueron que el 100\% de los investigados informó que ningúnexprounista no habría sido capaz de entrar enlaeducación superior; que, al completar el grado, luegofueron absorbidos por el mercado. No contento, buscaronotronivel diploma, elmaster para teneracceso a unmejorestatus social y laremuneración. Se sugiere que estosdatossirven para ampliar nuevasinvestigacionescondatos más cuantitativos y cualitativos.

PALABRAS ClAVE: ProUni. Política Pública. Programas de Postgrado.

\section{INTRODUÇÃO}

O Ensino Superior brasileiro passa por um processo de expansão. Várias estratégias estão em andamento, como o acréscimo de matrículas e a diversificação de cursos em instituições já em funcionamento, criação de novas Instituições de Ensino Superior (IES) sejam universidades, sejam institutos federais tecnológicos -, ou ainda, por meio de bolsas de estudo em IES privadas.

O Programa Universidade para Todos (ProUni) faz parte de um grande plano do governo federal no esforço de ampliar e democratizar o acesso ao Ensino Superior no país, não sendo uma iniciativa isolada. Com o ProUni, estão iniciativas como Programa de Apoio a Planos de Reestruturação e Expansão das Universidades Federais (Reuni) e a Universidade Aberta do Brasil (UAB), que são fundamentais no atual cenário educacional. (MORAES, 2011; ALMEIDA et al., 2011).

Com relação às desigualdades sociais, outras políticas públicas estão sendo implementadas, como Fundo de Financiamento Estudantil (Fies), Exame Nacional do Ensino Médio (ENEM), Políticas de Cotas para Negros e Indígenas (COTAS), ProUni (aqui aprofundado). Nesse contexto, são oferecidas cotas para afrodescendentes, indígenas e deficientes, enfrentando o desafio de romper ciclos de pobreza, agravados pelo não acesso à educação superior. (MORAES, 2011).

Segundo a Lei n. ${ }^{\circ} 11.096 / 2005$, o ProUni se constitui como uma política pública para a inclusão social, uma vez que possibilita o acesso dos sujeitos historicamente excluídos à educação superior. No entanto, pode ser considerada como política pública compensatória assim como a política de cotas. (PACIEVITCH, 2013).

No portal do Ministério Educação e Cultura (MEC), encontra-se a seguinte descrição sobre o programa: 
Tem como finalidade a concessão de bolsas de estudo integrais e parciais em cursos de graduação e sequenciais de formação específica, em instituições de ensino superior privadas. Criado pelo Governo Federal em 2004 e institucionalizado pela Lei n $^{\circ}$ 11.096, em 13 de janeiro de 2005 oferece, em contrapartida, isenção de tributos àquelas instituições que aderem ao Programa. (PROUNI PORTAL, 2005, p. 1) ${ }^{3}$.

O ProUni pode também ser considerado uma política pública de ação afirmativa, potencialmente inovadora. Esse programa é voltado aos estudantes egressos do Ensino Médio da rede pública ou da rede privada, na condição de bolsista integral (art. 2 da Lei n. ${ }^{\circ}$ 11.096/2005), estudantes portadores de necessidades especiais e professores da rede pública de ensino que se candidatem a cursos de licenciatura. Além disso, os candidatos devem atender ao critério socioeconômico, sendo a distribuição de bolsas integrais para os estudantes com renda per capita familiar de, no máximo, um salário mínimo e meio, e bolsas parciais para aqueles que possuem renda per capita familiar de, no máximo, três salários mínimos. A seleção dos candidatos à bolsa é feita por meio da prova do Exame Nacional do Ensino Médio (Enem), garantindo um processo de seleção ampliado para todo o país em termos de oferta das vagas.

Todavia, as políticas educacionais de inclusão ainda se mantêm como compensatórias, porque apenas ingressar na universidade não é solução para o acesso universal à educação. São necessários também programas que auxiliem a permanência do aluno na universidade, seja no espaço público, seja no privado.

Em termos de estratégias do governo federal para permanência do estudante, têm-se apenas duas modalidades: a Bolsa Permanência e o Fies. A Bolsa Permanência foi criada pela Lei n. ${ }^{\circ}$ 11.180/2005 como um benefício concedido a estudantes já selecionados para bolsa integral, matriculados em cursos presenciais com carga horária média igual ou superior a seis horas diárias de aula, com no mínimo seis semestres de duração, de acordo com os dados cadastrados pelas instituições de ensino junto ao MEC. A bolsa é uma forma de garantir a permanência de jovens que não têm condições de conciliar o trabalho com o estudo, em razão dos cursos que exigem dedicação integral. (MORAES, 2011).

Na visão de Faceira (2004), pensar o ProUni como política de inclusão social é ressaltar o significado dessa categoria teórica ("inclusão social") como sinônimo do resgate da cidadania, da plenitude dos direitos sociais, da participação social e política dos indivíduos (cidadãos) em todos os aspectos da sociedade. Segundo ela, a inclusão social é caracterizada pelo exercício da cidadania plena ou emancipatória, pela participação social, política e cultural, além do acesso aos direitos básicos.

Sousa (2003) e Gatti (2011) ressaltam que o ProUni tanto se caracteriza como um financiamento público estudantil com base na renúncia fiscal de parte do governo quanto uma estratégia de diversificação de fonte de financiamento, bem como uma ampliação e diferenciação de beneficiários. Além disso, trata-se de um programa que inclui sucessivos mecanismos jurídicos que interferem na prática social impulsionando-a para outros patamares de condições objetivas de acesso e permanência no Ensino Superior. Esses elementos fazem com que seja considerado um importante programa. Tanto é importante que, no ordenamento jurídico, já existe o princípio da vedação do retrocesso social garantido. ${ }^{4} \mathrm{O}$ governo federal

\footnotetext{
${ }^{4}$ Disponível em: 〈http://jus.com.br/951473-luciano-roberto-bandeira-santos/publicacoes>.. Acesso em: 13 mar. 2015.
} 
realiza um monitoramento permanente e acompanhamento de ações, a fim de garantir o êxito desse programa social. (PEREIRA FILHO, 2011). Entretanto, um acompanhamento mais direto dos beneficiários e dos resultados concretos na vida dos prounistas só é possível, mediante pesquisas, tanto quantitativas quanto qualitativas, que analisem casos de utilização e permanência no programa.

Em pesquisa encomendada pelo MEC, realizada pelo Instituto Ibope em março de 2009, que analisou o perfil dos alunos recém-formados com relação aos benefícios proporcionados pelo programa na vida deles, provou que o acesso ao mercado de trabalho mostrou-se exitoso. É dentro desse eixo de reflexão que este artigo se enquadra.

\section{Quadro Teórico}

Bourdieu (1998) argumenta que na sociedade existem diversas classes, cada uma tendo um determinado grau de capital cultural, ou seja, a sociedade se compõe ou estrutura em hierarquias sociais, econômicas e culturais. Considerando a existência de tais hierarquias, pode-se identificar a presença de elites, com amplas propriedades de capital cultural, econômico e social, que são os pequenos burgueses ou a classe média, com a pretensão de ascensão, e de classes populares, constituída por indivíduos movidos pela lógica da necessidade. Em níveis intermediários, há uma miríade de posições socioeconômicas e culturais em decorrência de diversos contextos históricos, de espaços de participação na sociedade e de vivências e perfis de indivíduos.

A expressão capital cultural é elaborada e utilizada por Bourdieu para analisar situações de classe na sociedade. O conceito é utilizado pelo sociólogo com enorme abrangência e ambiguidade, servindo para indicar as diversas maneiras em que a cultura reflete ou atua sobre as condições de vida dos indivíduos. De certa forma, o capital cultural serve para caracterizar subculturas de classes ou de setores de classe. Uma grande parte da obra de Bourdieu descreve minuciosamente a cultura - em um sentido amplo de gostos, estilos, valores, etc. - que são decorrentes das condições específicas de vida das diferentes classes, moldando as suas características e contribuindo para distinguir, por exemplo, a burguesia tradicional da nova pequena burguesia e esta, da classe trabalhadora. Vale observar, no entanto, que o capital cultural é mais do que uma subcultura de classe; é considerado como um recurso de poder que equivale e se destaca, no duplo sentido, de se separar de outros recursos, e de ter uma relevância especial, tendo como referência básica, especialmente, os recursos econômicos. Daí compreender-se o termo capital associado ao de cultura; uma analogia ao poder e ao aspecto utilitário relacionado à posse de determinadas informações, aos gostos e atividades culturais. Além do capital cultural, existiriam outras formas básicas de capital como: capital econômico, capital social e o capital simbólico. Juntas, estas formas de capital constituem as classes sociais ou o espaço multidimensional das formas de poder.

Para o sociólogo francês, a noção de capital cultural relaciona-se com a possibilidade de se compreender as desigualdades de desempenho escolar dos indivíduos oriundos de diferentes grupos sociais. Sua sociologia da educação se caracteriza, notadamente, pela diminuição do peso do fator econômico, em comparação ao peso do fator cultural, na explicação das desigualdades escolares. É na educação, segundo o autor, que se acumula o capital cultural, na forma de conhecimentos apreendidos em livros e acervos culturais, na convivência cultural, e na materialização em forma de diplomas. Para ele, o capital cultural 
pode existir sob três formas: no estado incorporado, no estado objetivado e no estado institucionalizado. (NOGUEIRA, NOGUEIRA, 2002; PIES, 2011; SILVA,1995).

O estado incorporado dá-se na forma de disposições duráveis de inculcação e assimilação, tendo como principais elementos constitutivos os gostos, domínio da língua culta e as informações sobre o mundo escolar. $\mathrm{O}$ patrimônio transmitido pela família inclui certos componentes que passam a fazer parte da própria subjetividade do indivíduo. O capital cultural incorporado constitui, na visão do autor, o elemento da herança familiar que teria o maior impacto na definição do destino escolar.

O estado objetivado inclui elementos externos ao indivíduo e que podem ser postos a serviço do sucesso escolar como o capital econômico tomado em termos dos bens e serviços a que ele dá acesso, como livros, pinturas, acervos, coleções. As possibilidades de usufruto desses bens culturais (visitas a museus, recitais, teatros, por exemplo) decorrem, também, do capital cultural incorporado.

Já o estado institucionalizado é formado basicamente por títulos escolares. O grau de investimento na carreira escolar está vinculado ao retorno provável que se pode obter com o título escolar.

Com esse olhar, iniciou-se a investigação.

\section{Espaço Empírico e Sujeitos}

O estudo foi realizado em uma IES do Rio Grande do Sul, a Universidade Regional Integrada do Alto Uruguai e das Missões (URI), especificamente a unidade situada em Frederico Westphalen, a noroeste do estado. Possui quatro campi (Erechim, Santo Ângelo, Frederico Westphalen, Santiago) e duas extensões (Cerro Largo, São Luiz Gonzaga). A instituição conta com cursos de graduação e programas de pós-graduação lato e stricto sensu.

A URI é uma IES de natureza jurídica privada, comunitária e sem fins lucrativos. Como núcleo, além dos gestores, docentes e funcionários, a URI em 2013 contou com 42.856 estudantes, sendo 8.512 matriculados nos cursos de licenciatura, dos quais 1.263 eram prounistas.

A URI abrange um universo de mais de 100 municípios do Rio Grande do Sul e oeste de Santa Catarina, sendo uma região basicamente povoada por descendentes de colonos alemães e italianos. Conta também com uma população indígena na divisa do estado do Rio Grande do Sul e Santa Catarina (Iraí, Vicente Dutra). O estudo foi realizado na região que abrange um total de 3 mil alunos, distribuídos em 25 cursos, atingindo 55 municípios, além do município de Frederico Westphalen. Desses cursos, somente em um deles teve a participação indígena na graduação regular (licenciatura): o do Plano Nacional de Formação de Professores da Educação Básica (Parfor).

Além da URI/FW, a cidade conta com outras ofertas de Ensino Superior: a Universidade de Ensino a Distância (UNOPAR EaD), a Universidade Estadual do Rio Grande do Sul (UERGS), com quatro cursos e a Universidade Federal de Santa Maria (UFSM), com seu Centro de Educação Superior Norte-RS (CESNORS), possuindo cinco cursos. 
Na região em que está situada, a URI/FW é a mais antiga, sendo a que oferece mais cursos e também a que possui mais condições de ingresso com o ProUni e o FIES. Para terem acesso a essas políticas, os acadêmicos devem preencher e justificar uma grande quantidade de documentos pessoais e familiares que ficam na IES e são sigilosos.

O stricto sensu em Educação na URI/FW foi implantado em 2010, estabelecendo a área de concentração em Educação com as linhas de pesquisa em Formação de Professores e Práticas Educativas e Políticas Públicas e Gestão da Educação. O início do programa ocorreu em 2011. Os ingressantes na pós-graduação foram em número de 16 alunos por turma. $\mathrm{O}$ número de alunos de 2011 a 2013 totalizou 48. O caso em estudo é constituído de oito mestrandos que ingressaram entre 2011 (primeira turma) e 2013.

Para uma contextualização da região do estudo, faz-se necessário apontar dados da sua situação econômica. Essa é constituída pelas indústrias de lapidação de pedras semipreciosas, e de ração animal. Possui abatedouros de suínos, bovinos e aves, além de uma área agrícola bastante desenvolvida e diversificada, caracterizando-se pela pequena propriedade rural, as agroindústrias familiares, na avicultura, piscicultura e a agroindústria de pequeno porte.

Frederico Westphalen possui aproximadamente 30 mil habitantes (IBGE, 2013), caracterizando-se como uma cidade interioriana, tranquila, onde ainda não são disponibilizados transportes coletivos, não havendo inclusive semáforos.

Por causa da sua localização, a cidade tem deficiência de atividades e opções culturais, não possuindo cinema, teatro, exposições e/ou acervos de artes, shows musicais, e tampouco shopping center. Conta com uma única livraria (a livraria acadêmica), localizada dentro na universidade. As outras cidades onde residem os participantes do estudo possuem menos habitantes ainda, concentrando-se em atividades agrícolas, apresentando, por isso, menos condições culturais do que a cidade sede. Portanto, há uma real dificuldade de acesso, na região, aos bens culturais por parte da maioria dos ex-prounistas que alcançaram a pós-graduação na URI/FW.

\section{CONCEPÇÕES TEÓRICO-METODOLÓGICAS}

Este estudo se caracterizou como uma pesquisa quantitativa de caráter descritivo e como estudo de caso, que teve por finalidade registrar e analisar fenômenos fundamentados nas ideias de Bourdieu na qualidade de capital cultural.

A amostra deste estudo se constituiu de forma não probabilística e intencional por oito mestrandos ex-prounistas que ingressaram no PPG Educação da URI, de Frederico Westphalen, no período de 2011 a 2013. Trata-se, portanto de um método de coleta censitária. 
O grupo em estudo compõe a totalidade da população de ex-prounistas que ingressaram no PPG Educação da URI no período em estudo. Os dados foram coletados por meio de um questionário fechado ${ }^{5}$, com perguntas inspiradas na pesquisa de Almeida et al. (2011).

A tabulação dos dados foi manual e utilizou-se da estatística descritiva (frequência e percentagem) pelo emprego do programa Microsoft Excel, no processamento das seguintes informações: área de formação, procedência de rede de ensino, gênero, raça, idade, ano de ingresso, modalidade de bolsa, local de residência, turno em que estudaram, possibilidade de ingresso no Ensino Superior, situação de trabalho e benefícios do ProUni. A análise apresentada a seguir baseia-se nos dados globais que apontam para o perfil dos ex-prounistas na perspectiva de Bourdieu.

\section{APRESENTAÇÃO E INTERPRETAÇÃO DOS RESULTADOS}

Neste tópico apresentamos o perfil dos ex-prounistas investigados. Cabe salientar que cada prounista, quando do ingresso, preencheu uma documentação para a IES, colocando dados pessoais e familiares, que são sigilosos para qualquer pesquisador. Decorre desse fato a importância desta pesquisa que traça o perfil dos ex-prounistas ingressantes na pós-graduação durante o período de 2011 a 2013.

\section{TABELA 1}

Área de formação na licenciatura dos ex-prounistas mestrandos do PPGEDU-URI/FW ingressantes 2011-2013

\begin{tabular}{lccccc}
\hline Área de formação na licenciatura & 2011 & 2012 & 2013 & Total & $\%$ \\
\hline Matemática & 1 & & & 1 & 12,5 \\
Filosofia & 1 & 2 & & 3 & 37,5 \\
Pedagogia & & & 2 & 2 & 25 \\
Educação Física & & & 1 & 1 & 12,5 \\
Química & & & 1 & 1 & 12,5 \\
\hline Total & 2 & 2 & 4 & 8 & 100 \\
\hline
\end{tabular}

Fonte: Das autoras, pesquisa de campo.

Ficaram assim distribuídos: 25\% em 2011, 25\% em 2012, e 50\% em 2013, totalizando $100 \%$ do universo de oito mestrandos. Ocorreu, portanto, um progressivo aumento de prounistas no mestrado em Educação de 2011 a 2013.

\footnotetext{
${ }^{5}$ Questionário: Dados de identificação: Nome... Idade... Raça...; Você cursou o Ensino Médio em escola pública (...) ou privada (...)? Em que município você cursou o Ensino Médio? Você nasceu em que município? ... Você reside em Frederico Westphalen? Sim (...) Não (...) Onde?(...) Seus pais incentivaram você a estudar. Sim (...) Não (...) Qual a profissão dos seus pais? Mãe... Pai... Por que você escolheu a licenciatura? Pelo acesso (...) Por vontade (...) Qual área? ... Ano de ingresso (...) Turno do curso: Diurno (...) Noturno (...) Você teve bolsa para estudar? Sim (...) Não (...) Qual? ... Total/Parcial (...) Ingressaria sem bolsa para estudar no Ensino Superior? Sim (...) Não (...) Você trabalha? Sim (...) Não (...) Onde? Quais os benefícios do ProUni para você?
} 
Quanto à área de formação em licenciatura, dos ex-prounistas cursaram: três $(37,5 \%)$ Filosofia, dois (25\%) Pedagogia, um (Matemática) 12,5\%, um (12,5\%) Educação Física, e um $(12,5 \%)$ Química. Os pró-graduandos, portanto, são oriundos predominantemente de licenciaturas em Filosofia e Pedagogia.

TABELA 2 - Procedência de Rede de Ensino das escolas de Ensino Médio em que os ex-prounistas estudaram

\begin{tabular}{lccccc}
\hline Escola Ensino Médio & 2011 & 2012 & 2013 & Total & $\%$ \\
\hline Pública & 2 & 2 & 4 & 8 & 100 \\
Privada & & & & 0 & 0 \\
\hline Total & 2 & 2 & 4 & 8 & 100 \\
\hline
\end{tabular}

Fonte: Das autoras, pesquisa de campo.

Todos os ex-prounistas realizaram seus estudos do Ensino Médio em escolas da rede pública e foram incentivados pelos pais. Esta característica é critério preponderante para ingresso no ProUni.

\section{TABELA 3}

Gênero dos ex-prounistas das licenciaturas, mestrandos do

PPGEDU-URI/FW ingressantes 2011-2013

\begin{tabular}{lccccc}
\hline Sexo & 2011 & 2012 & 2013 & Total & $\%$ \\
\hline Masc & 1 & & & 1 & 12,5 \\
Fem & 1 & 2 & 4 & 7 & 87,5 \\
\hline Total & 2 & 2 & 4 & 8 & 100 \\
\hline
\end{tabular}

Fonte: Das autoras, pesquisa de campo.

Entre todos os ex-prounistas que ingressaram na pós-graduação em Educação há uma predominância de mulheres, o que confirma outros estudos na literatura acerca do gênero de estudantes de licenciaturas.

\section{TABELA 4}

Raça dos ex-prounistas, mestrandos do PPGEDU-URI/FW ingressantes 2011-2013

\begin{tabular}{lccccc}
\hline & 2011 & 2012 & 2013 & Total & $\%$ \\
\hline Branca & 2 & 2 & 4 & 8 & 100 \\
Outras & & & & 0 & 0 \\
\hline Total & 2 & 2 & 4 & 8 & 100 \\
\hline
\end{tabular}

Fonte: Das autoras, pesquisa de campo. 
No período de 2011 a 2013 não houve registro de ex-prounistas de outras raças além da branca. Cabe salientar que a região onde a pesquisa foi realizada é de colonização alemã e italiana, com um reduzido número de negros. Embora existam indígenas na região, no período pesquisado não houve acesso algum deles à pós-graduação.

TABELA 5

Idade dos ex-prounistas, mestrandos do PPGEDU-URI/FW ingressantes 2011-2013

\begin{tabular}{lccccc}
\hline Idade & 2011 & 2012 & 2013 & Total & $\%$ \\
\hline 23 anos & & & 1 & 1 & 12,5 \\
24 anos & & & 2 & 2 & 25 \\
26 anos & 2 & & 1 & 1 & 12,5 \\
27 anos & 2 & 1 & & 2 & 25 \\
28 anos & & 1 & & 1 & 12,5 \\
50 anos & 2 & 2 & 4 & 8 & 100 \\
\hline Total & & & & & \\
\hline
\end{tabular}

Fonte: Das autoras, pesquisa de campo.

A distribuição da faixa etária está concentrada entre 24 a 27 anos, com 62,5\%, o que caracteriza o grupo como formado, predominantemente, por adultos jovens.

TABELA 6

Ano de Ingresso no Ensino Superior dos ex-prounistas mestrandos do PPGEDU-URI/FW ingressantes 2011-2013

\begin{tabular}{lccccc}
\hline Ingresso Ensino Superior & 2011 & 2012 & 2013 & Total & $\%$ \\
\hline 2001 & & & 1 & 1 & 12,5 \\
2004 & 2 & 1 & & 1 & 12,5 \\
2005 & & 1 & 1 & 2 & 37,5 \\
2008 & & & 1 & 1 & 25 \\
2009 & 2 & 2 & 4 & 8 & 12,5 \\
\hline Total & & & & & \\
\hline
\end{tabular}

Fonte: Das autoras, pesquisa de campo.

O ingresso no Ensino Superior situou-se entre 2001 e 2009, com maior concentração no ano de 2005, quando se iniciou o ProUni na URI/FW. 


\section{TABELA 7}

Modalidade de bolsa dos ex-prounistas mestrandos do PPGEDU-URI/FW ingressantes 2011-2013

\begin{tabular}{lccccc}
\hline Modalidade Bolsa & 2011 & 2012 & 2013 & Total & $\%$ \\
\hline $100 \%$ & 1 & 2 & 3 & 6 & 75,0 \\
$50 \%$ & 1 & & 1 & 2 & 25,0 \\
\hline Total & 2 & 2 & 4 & 8 & 100 \\
\hline
\end{tabular}

Fonte: Das autoras, pesquisa de campo.

A maioria dos ex-prounistas, $75 \%$ recebeu bolsas de $100 \%$, o que comprova sua carência econômica, ou seja, em termos do quadro teórico adotado caracteriza a ausência de capital econômico. Por outro lado, esse dado reforça o quanto essa política precisa acentuar e concentrar recursos em bolsas integrais.

\section{TABELA 8}

Local de residência de ex-prounistas, mestrandos do PPGEDU-URI/FW ingressantes 2011-2013

\begin{tabular}{lccccc}
\hline Procedência & 2011 & 2012 & 2013 & Total & $\%$ \\
\hline Frederico Westphalen-RS & 1 & 1 & 1 & 3 & 37,5 \\
Fora da sede (rural) & 1 & 1 & 3 & 5 & 62,5 \\
\hline Total & 2 & 2 & 4 & 8 & 100 \\
\hline
\end{tabular}

Fonte: Das autoras, pesquisa de campo.

Quanto à procedência dos ex-prounistas, 37,5\% residem na sede, Frederico Westphalen, onde está situada a URI, e 62,5\% vieram de outras localidades rurais (Cerro Grande, Santo Augusto, Caiçara, Nonoai, Rondinha). Quanto à atividade econômica familiar, 100\% deles são filhos de pequenos agricultores.

TABELA 9

Turno em que os ex-prounistas estudaram nos cursos de licenciatura

\begin{tabular}{lccccc}
\hline Turno de estudo da graduação & 2011 & 2012 & 2013 & Total & $\%$ \\
\hline Diurno & & & & 0 & 0 \\
Noturno & 2 & 2 & 4 & 8 & 100 \\
\hline Total & 2 & 2 & 4 & 8 & 100 \\
\hline
\end{tabular}

Fonte: Das autoras, pesquisa de campo. 
Todos os participantes, ou seja, $100 \%$, fizeram sua formação na licenciatura à noite. A URI é a única IES da região que oferta cursos de licenciatura. Estes ocorrem à noite por causa do deslocamento dos alunos advindos de vários municípios.

TABELA 10

Possibilidade de ingresso no Ensino Superior dos ex-prounistas mestrandos do PPGEDU-URI/FW sem a bolsa ProUni

\begin{tabular}{lccccc}
\hline Situação econômica para ingresso & 2011 & 2012 & 2013 & Total & $\%$ \\
\hline Matemática & $1 \mathrm{~N}$ & & & 1 & 12,5 \\
Filosofia & $1 \mathrm{~N}$ & $2 \mathrm{~N}$ & & 3 & 37,5 \\
Pedagogia & & & $2 \mathrm{~N}$ & 2 & 25 \\
Educação Física & & & $1 \mathrm{~N}$ & 1 & 12,5 \\
Química & & & $1 \mathrm{~N}$ & 1 & 12,5 \\
\hline Total & 2 & 2 & 4 & 8 & 100 \\
\hline
\end{tabular}

Fonte: Das autoras, pesquisa de campo.

Quando indagados acerca das possibilidades de cursar o Ensino Superior sem o apoio do ProUni, $100 \%{ }^{6}$ dos mestrandos indicaram que não teriam possibilidade de estudar sem uma bolsa de estudos, tendo em vista que seus pais são pequenos agricultores.

TABELA 11

Situação de trabalho dos ex-prounistas, mestrandos do PPGEDU-URI/FW ingressantes 2011-2013

\begin{tabular}{lcccccc}
\hline Trabalho & & 2011 & 2012 & 2013 & Total & $\%$ \\
\hline Atuam como Professores & (Ensino & 2 & 1 & 3 & & \\
Superior) & & & & & 6 & 75 \\
Só estudam (bolsistas) & & & 1 & 1 & 2 & 25 \\
\hline Total & & 2 & 2 & 4 & 8 & 100 \\
\hline
\end{tabular}

Fonte: Das autoras, pesquisa de campo.

Entre os participantes do estudo, seis $(70,0 \%)$ estão atuando como professores - em escolas da rede particular (2) e estadual (4). Os outros dois estão somente estudando, mas com auxílio de bolsa de estudos. Esse dado sugere a importância, para este grupo em análise, do apoio mediante bolsas do Programa, em especial, para os que escolhem cursos de licenciatura, os quais, não só se titulam, mas também exercem a profissão de professores e buscam a continuidade de formação na pós-graduação.

${ }^{6} \mathrm{~N}$ para não e $\mathrm{S}$ para Sim.

\begin{tabular}{l|l|l|l|l|l|l} 
(C) ETD -Educ. Temat. Digit. & Campinas, SP & v.17 & n.3 & p. 596-613 & set./dez.2015 & ISSN 1676-2592
\end{tabular} 


\section{TABELA 12}

Benefícios do ProUni para os ex-prounistas mestrandos do PPGEDU-URI/FW sem a bolsa ProUni (respostas múltiplas)

\begin{tabular}{lccccccc}
\hline & Matemática & Filosofia & Pedagogia & Ed. Física & Química & Total & $\%$ \\
\hline Profissão & 1 & 3 & 2 & 1 & 1 & 8 & 100 \\
Sonho & 1 & 3 & 2 & 1 & 1 & 8 & 100 \\
Mudança Social & 1 & 3 & 2 & 1 & 0 & 7 & 87,5 \\
$\begin{array}{l}\text { Crescimento } \\
\text { pessoal }\end{array}$ & 0 & 3 & 2 & 1 & 0 & & \\
Oportunidade & 1 & 0 & 2 & 1 & 1 & 5 & 62,5 \\
\hline
\end{tabular}

Fonte: Das autoras, pesquisa de campo.

Dos participantes pesquisados, $100 \%$ responderam $^{7}$ que o sonho de ingressar no Ensino Superior foi atingido, assim como $100 \%$ responderam que a escolha ocorreu por ser a profissão desejada. Entre esses, 87,5 \% responderam ainda que houve uma mudança social em suas vidas, sendo que $75 \%$ acrescentaram ainda um crescimento pessoal. Dos respondentes, 62,5\% afirmaram que o benefício do ProUni foi a oportunidade de ingresso.

\section{Discussão dos resultados}

Cem por cento dos investigados vieram de escolas de Ensino Médio da rede pública. Tal dado sugere o papel relevante da escola pública na região, em termos de oportunizar experiências importantes na forma de interação social e vivências culturais enriquecedoras.

Entre os investigados, 37,5 \% são de Frederico Westphalen e 62, $5 \%$ de municípios rurais adjacentes à sede da IES, dela distantes em até 100 quilômetros. A totalidade dos pesquisados são oriundos de famílias rurais cujos pais são agricultores, mas que marcadamente incentivaram seus filhos a estudar. Apoiando-se em Bourdieu no que se refere ao poder simbólico, pode-se dizer que esses investigados (desprovidos de heranças familiares consistentes em termos de capital econômico e cultural) fazem parte de um ideário em que se produz e reproduz uma crença de que eles são sujeitos excluídos. (BOURDIEU, 1989). Por outro lado, vale lembrar a contribuição de sociólogos contemporâneos que trabalham com as concepções de Bourdieu, mas questionam a possibilidade de certo automatismo na transmissão, de uma geração para a outra, de recursos culturais. Aqui se insere a dimensão de busca pessoal de que os investigados parecem portadores.

\footnotetext{
O sentido que cada aluno atribui à escola e à atividade de aprender, o que não é diretamente dedutível de seu pertencimento social, mas sim algo construído ao longo de uma história de vida singular. Haveria alunos - mais aptos ao sucesso escolar para quem o saber possui valor intrínseco e é buscado por si mesmo, enquanto outros - que se situam numa lógica utilitarista - só confeririam valor às aprendizagens escolares em função de recompensas externas. (NOGUEIRA, 2011, p. 81).
}

\footnotetext{
${ }^{7} \mathrm{Na}$ construção do questionário, especificamente quanto aos benefícios da bolsa ProUni, inspiramo-nos em categorias já apresentadas nas pesquisas de Almeida et al. (2011) assim como de Farias et al. (2011).
} 
Há portanto que considerar, para além do papel da herança, a interveniência da dimensão pessoal.

O papel das famílias na construção do capital social tem sido abordado sob dois ângulos segundo Bonamino, Alves e Franco (2010). O primeiro examina a construção do capital social no interior das redes familiares e a importância disso para o desenvolvimento escolar e cognitivo dos filhos. O segundo ângulo focaliza o papel das famílias na construção de capital social extrafamiliar, o qual pode ser construído em redes fora do lar e no interior de contextos econômicos, estatais e comunitários, como: família, amigos, escola, igreja, associações, clubes e os ganhos obtidos em decorrência da participação nesses grupos. No caso em estudo, os exprounistas possivelmente apropriam-se do capital social oportunizado por suas famílias, assim como o favorecido pela escolarização e pelas relações sociais por meio delas fomentadas. Fora da rede familiar, os ganhos foram sendo agregados na escola e na comunidade, ampliando o capital cultural em seus estados objetivados e institucionalizados.

Os participantes do estudo são todos provenientes dos cursos de licenciatura (Matemática, Filosofia, Pedagogia, Educação Física e Química) e todos realizaram seus cursos no turno da noite. A saída do status de filho de agricultores e obter o de professor, para esses jovens, possibilitou uma nova relação indivíduo-sociedade. Trata-se da busca de um novo habitus por meio de escolhas, de tomada de decisões, de valores que auxiliam o indivíduo a circular em espaços sociais mais largos e diversificados.

Pode-se levantar a hipótese de que os aqui investigados saíram de um estado de necessidades e atingiram um outro patamar, caracterizado com os ganhos de títulos escolares, cujo retorno provável está vinculado ao grau de investimento realizado na carreira escolar.

O sexo feminino foi predominante na pesquisa realizada (87,5\%), confirmando os dados estatísticos apresentados na literatura, os quais afirmam que nas licenciaturas há o predomínio de mulheres. Quanto ao quesito raça, todos os integrantes são brancos, confirmando o fato de que a população da região é na sua maioria descendentes de colonos alemães e italianos. Quanto à idade, são adultos jovens, na maioria, na faixa etária entre $20 \mathrm{e}$ 30 anos.

Estes dados encontrados estão muito próximos do perfil dos prounistas discutido por Farias et al. (2011), tanto em relação à predominância feminina quanto em termos de faixa etária. Afirmam eles que "o programa está atingindo perfeitamente o público jovem a que se destina" (FARIAS et al., 2011, p. 87), com predominância de 36,8\% de estudantes entre 21 e 24 anos e $24,6 \%$, com até 20 anos. Como a pesquisa desses autores refere-se a alunos que estão realizando a graduação, cujos cursos têm a duração de 3 a 4 anos, é coerente que, na pósgraduação, os ex-prounistas situem-se na faixa de 24 a 27 anos.

O ano de ingresso no Ensino Superior ficou entre 2005 e 2006, nos quais se iniciou o ProUni na Universidade onde este estudo foi realizado. Esse fato reforça a importância desse programa para o ingresso de estudantes sem possibilidades econômicas, configurando o quanto ele favorece o acesso ao Ensino Superior. 
Por outro lado, observa-se que, progressivamente, o ingresso na pós-graduação ocorreu imediatamente após a conclusão da licenciatura para os últimos ingressantes. É importante observar que o mestrado nessa IES iniciou-se em 2011, o que abriu novas possibilidades aos prounistas oriundos de licenciaturas para avançarem em seu estudo e continuar construindo em sua singular história de vida uma relação positiva com a escola e com o saber.

Também é importante salientar que $75 \%$ estudaram na licenciatura com $100 \%$ de bolsa ProUni, evidenciando suas carências econômicas, visto que são oriundos de pequenas famílias de agricultores. Esses dados confirmam que o capital cultural foi construído por um conjunto de estratégias, valores e disposições não decorrentes diretamente de seu pertencimento social, mas de um amálgama de influências comunitárias, escolares e de perfil pessoal.

O perfil dos ex-prounistas focados nesta pesquisa difere daquele debatido por Farias et al. (2011) quanto ao turno do curso de graduação e modalidade de bolsa. Os dados por eles apresentados informam que 63,8\% estudaram no noturno e $88,9 \%$ usufruíram bolsa integral. As características do perfil encontrado no presente estudo estão diretamente relacionadas com os cursos frequentados e com a estrutura curricular da IES do estudo - $75 \%$ com bolsa integral e a totalidade frequentou curso superior noturno.

Dos pesquisados, $75 \%$ ingressaram no mestrado já como professores de escola básica, evidenciando que com a graduação foi possível ingressar no mercado de trabalho. Esse achado converge com os dados de Pacievitch (2013), segundo os quais o ProUni é uma política compensatória, porém válida como estratégia para possibilitar aos alunos de baixa renda o acesso ao Ensino Superior e, consequentemente, ao mercado de trabalho.

Ficou evidenciado na pesquisa que, ao concluir a graduação, esses profissionais foram absorvidos pelo mercado de trabalho, possibilitando uma geração de renda e um status social. Não contentes, buscaram outro nível de diplomação (novo investimento) para terem acesso a outras melhorias na posição social e na remuneração.

Todos os alunos envolvidos na pesquisa (100\%) indicaram que não teriam possibilidade de realizar um curso universitário sem o ProUni, visto que são carentes economicamente. Esse programa possibilitou que oito ex-prounistas ingressassem na pós-graduação em Frederico Westphalen. Este fato confirma a pesquisa de Pacievitch (2013 p. 6), que afirma: a "maior potencialidade do programa é dar perspectivas de vida para aqueles que não teriam uma chance" [...] e ainda "possibilidades de transformações de vidas". Segue a autora retomando seus entrevistados: "tenho uma profissão, sou pedagoga. Graças ao ProUni, daqui a dois anos serei Mestre em Educação". (PACIEVITCH, 2013, p. 7).

Nos depoimentos dos questionários desta investigação, destacam-se: “Meus pais são agricultores e não teriam condições de me auxiliarem financeiramente para eu estudar. Se não fosse o ProUni eu não conseguiria"; "Foi um sonho! Sempre acreditei que se pudesse ser professora poderia ajudar meus pais"; "Eu fui a primeira, meus pais nunca estudaram"; "Meus pais me incentivavam a estudar, a buscar uma oportunidade"; "Você precisa estudar para sair dessa vida [...] é só estudando para melhorar de vida, ter uma profissão". 
Esses depoimentos sugerem a possibilidade de o ProUni fomentar a emergência dos

casos "estatisticamente improváveis" de sucesso escolar em meios populares, [os quais] demonstraram que certos fatores associados à história, às atitudes e ao modo de funcionamento das famílias podem se revelar tão importantes quanto o peso da origem sociocultural. (NOGUEIRA, 2011, p. 82).

A partir do pensamento de Bourdieu, é possível situar os capitais culturais nos estados incorporados, objetivados e institucionalizados nesta investigação. No incorporado, visualizase o elemento constitutivo de informações sobre o mundo escolar e de linguagem culta, já que eles são filhos de pequenos agricultores que incentivaram seus filhos a estudar. $\mathrm{O}$ estado objetivado caracterizou-se pelos bens e serviços externos ao indivíduo, adquiridos e representados pelo sucesso escolar que veio graças aos estudos, da dedicação aos livros e pelo acesso à cultura escolar, saindo do seu meio para ingressarem no Ensino Médio e, posteriormente, na universidade. O estado institucionalizado caracterizou-se com os diplomas de Ensino Médio e de Ensino Superior, que oportunizaram o ingresso na pós-graduação.

\section{CONCLUSÃO}

Segundo Sousa (2003), uma primeira geração de estudos sobre a avaliação de políticas públicas foi focada nos fracassos. A autora afirma também que, para uma segunda geração de estudos, era necessário avançar questionando acerca dos impactos sobre os resultados dessas políticas, e mais, era necessário transitar e fazer um balanço de fracassos e sucessos de tais políticas para avançar nas investigações. Piotto (2009) aponta que há poucas investigações sobre sucesso escolar ou trajetórias escolares bem-sucedidas de camadas populares.

Foi essa direção que esta investigação buscou seguir: compreender o sucesso de oito mestrandos ex-prounistas, tentando ver a inclusão e a permanência desses alunos como possível e visível.

O estudo realizado nessa região do Alto Uruguai mostrou que esses oito ex-prounistas, além de terem acesso aos estudos superiores, permaneceram e foram além do esperado, ou seja, ingressaram na pós-graduação na conquista de mais um diploma. O ProUni teve relevância na vida desses sujeitos, sendo que essa política pública para eles foi fundamental, porque afirmaram que sem ela não teriam tido condições de ingressar no Ensino Superior. Essa conclusão também podemos encontrar em Gatti (2011), ao afirmar, em sua pesquisa, que os contemplados com a bolsa ProUni obtiveram benefícios concretos na vida e no trabalho.

Nesta pesquisa tivemos a intenção de apresentar o acesso, a permanência dos acadêmicos e a efetividade desta política pública na região, $\mathrm{O}$ foco foi o capital social e cultural na perspectiva de Bourdieu. Viu-se a relevância que o ProUni teve na vida desses sujeitos, pois sem ele tal mobilidade social dificilmente teria ocorrido. A região saiu ganhando, uma vez que os licenciados que ingressaram na pós-graduação agregaram ganhos sociais e culturais e continuaram, em sua maioria, na docência da Educação Básica. Esta política pública, nessa região, para esses investigados, fez diferença. 
Consideramos ainda que não se pode levar adiante uma reflexão fechada dos usos do capital cultural. Bourdieu utiliza o conceito de capital cultural com certa ambiguidade e abrangência, servindo para indicar diversas maneiras em que a cultura reflete ou atua sobre as condições de vida dos indivíduos. Concordamos, entretanto, com Nogueira (2011, p. 82) ao afirmar que "o paradigma da reprodução não foi ultrapassado, mas (...) redesenhado". A investigação aqui apresentada, a partir de um método de coleta censitário, apontou que $75 \%$ tinham carência econômica vindo de agricultura familiar, 62,5\% eram de municípios entre 2.590 e 5 mil habitantes e que todos estudaram à noite para poderem ascender de classe social. Considerando apenas esses dados descritivos, estaríamos reafirmando a perspectiva da reprodução. Entretanto o contexto argumentativo deste artigo discute o capital cultural em uma perspectiva mais compreensiva e situa-se no contexto de uma política pública de apoio a populações vulneráveis de forma a terem acesso ao Ensino Superior. O estudo demonstrou a efetividade do ProUni, considerando a totalidade de prounistas aqui estudados e que estão frequentando o mestrado em educação da URI/FW.

Os dados levantados sugerem também a necessidade de avançar em estudos que busquem entender práticas e perfis culturais dos prounistas de sucesso e descrevam o sentido atribuído pelos estudantes que alcançam patamares sociais e culturais mais altos em relação a gerações anteriores às de suas famílias quanto à escolarização, aos estudos e a bens culturais.

O capital cultural reflete bem o realce dado por Bourdieu aos intangíveis e às minúcias da cultura de classe e, também, ao papel do sistema escolar para a região investigada. Houve melhora, superaram o habitus. Sabemos que as correlações estabelecidas por Bourdieu entre posições sociais, ações práticas e habitus precisam ser revisitadas e cotejadas com a múltipla realidade educacional brasileira. Diversas análises do próprio Bourdieu e de outros autores mostram que, essas informações também podem se constituir em um mecanismo de mudança, contribuindo para a mobilidade social. Caracteriza-se, assim, o que foi chamado de paradoxo da teoria de Bourdieu: a cultura ora atuando como mecanismo de reprodução das condições sociais, ora como um veículo de mudança social. (SILVA,1995).

Com esses dados apresentados, mostramos que o sucesso desses oito ex-prounistas contribuiu de modo significativo para o PPG em Educação, para a URI/FW e para a região do Alto Uruguai. Os estudantes pesquisados saíram do estado de necessidade apontado por Bourdieu, tendo condições de uma profissionalização na área da Educação e, demonstrando importante estratégia de valorização da escola e de acúmulo de capital cultural.

\section{REFERÊNCIAS}

ALMEIDA, Cleide; DIAS, Elaine Dal Mas; PETRAGLIA, Izabel; RIZZO, Lupércio. Contexto educacional e inclusão social. In: LIMENA, Maria Margarida, RODRIGUES, Maria Lucia, PETRAGLIA, Izabel, ALMEIDA, Cleide (Org.). Prouni e inclusão social. São Paulo: Xamã, 2011. p. 11-22.

BONAMINO, Alícia; ALVES, Fátima; FRANCO, Creso; CAZELLI, Sibele. Os efeitos das diferentes formas de capital no desempenho escolar: um estudo à luz de Bourdieu e de Coleman. Revista Brasileira de Educação, Rio de Janeiro, RJ, v. 15, n. 45, p. 487-499. set./dez. 2010. Disponível em: < http://goo.gl/c64EBp>. Acesso em: 10 out. 2013. ISSN 1809-449X. 
BOURDIEU, Pierre. Escritos de educação. Petrópolis: Vozes, 1998.

BOURDIEU, Pierre. O poder simbólico. Lisboa, DIFEL, 1989.

BRASIL. Lei n. 11.096, de 13 de janeiro de 2005. Institui o Programa Universidade para Todos PROUNI, regula a atuação de entidades beneficentes de assistência social no Ensino Superior; altera a Lei no 10.891, de 9 de julho de 2004, e dá outras providências. Brasília, 2005. Disponível em: < http://goo.gl/ZnpPLi>. Acesso em: 9 nov. 2013.

FACEIRA, Lobelia da Silva. Programa Universidade Para Todos: Política de Inclusão Acadêmica e Social? Novo Enfoque, São Paulo, SP. Disponível em: 〈http://goo.gl/9OnfTP $>$. Acesso em: 7 jul. 2013. ISSN 1808-3501.

FARIAS, Márcia Helena, SIMÕES, Paulo Roberto, SANTOS, Nadja Codá dos; MENEZES, Rubem Araújo de. Caracterização de alunos bolsistas Prouni nos municípios pesquisados. In: LIMENA, Maria Margarida, RODRIGUES, Maria Lucia, PETRAGLIA, Izabel; ALMEIDA, Cleide (Org.). Prouni e inclusão social. São Paulo: Xamã, 2011. p. 87-112.

GATTI, Bernadete Angelina; BARRETTO, Elba Siqueira de Sá; ANDRE, Marli Eliza Dalmazo de Afonso. Políticas docentes no Brasil. Brasília: Unesco, 2011.

GATTI, Bernadete Angelina. Educação Superior, seus sentidos e o Prouni. In: LIMENA, Maria Margarida, RODRIGUES, Maria Lucia, PETRAGLIA, Izabel; ALMEIDA, Cleide (Org). Prouni e inclusão social. São Paulo: Xamã, 2011, p. 123-136.

MORAIS, Fernando Antonio de Andrade. O ProUni e a promoção da inclusão social. Âmbito Jurídico, Rio Grande, v. 14, n. 92, set. 2011. Disponível em: < http://goo.gl/16D6P5>. Acesso em: 9 jan. 2014.

NOGUEIRA, Claudio Marques Martins; NOGUEIRA, Maria Alice. A sociologia da educação de Pierre Bourdieu: limites e contribuições. Educação \& Sociedade, Campinas, SP, v. 23, n. 78, p. 15-35. abr. 2002. Disponível em: 〈 http://goo.gl/jGD9W>. Acesso em: 10 out. 2013. ISSN 1678-4626.

NOGUEIRA, Claudio Marques Martins; NOGUEIRA, Maria Alice. Bourdieu e a educação. 3. ed. Belo Horizonte: Autêntica, 2009.

NOGUEIRA, Maria Alice. Capital cultural. In: ZANTEN, Agnés Van. Dicionário de educação. Petrópolis: Vozes, 2011. p. 80-82.

PACIEVITCH, Thais. Políticas de acesso e permanência no ensino superior: as experiências de uma bolsista do ProUni. Disponível em: 〈 http://goo.gl/OW39ks $>$. Acesso em: 18 out. 2013.

PEREIRA FILHO, Ednaldo da Silva. Perfil de jovens universitários bolsistas do ProUni: um estudo de caso na Unisinos. 2011. 131 f. Tese (Doutorado em Ciências Sociais) Universidade do Vale do Rio dos Sinos, Unisinos, São Leopoldo, RS, 2011. Disponível em: < http://goo.gl/6zH0PT>. Acesso em: 26 out. 2013. 
PIES, Neri. Capital cultural e educação em Bourdieu. 2011. 69 f. Dissertação (Mestrado em Educação) - Faculdade de Educação, Universidade de Passo Fundo, Passo Fundo, RS, 2011.

RODRIGUES, Maria Lucia. O Programa Universidade para Todos: limites e proposições. In: LIMENA, Maria Margarida; RODRIGUES, Maria Lucia; PETRAGLIA, Izabel; ALMEIDA, Cleide (Org.). Prouni e inclusão social. São Paulo: Xamã, 2011. p. 113-120.

SANTOS, Luciano Roberto Bandeira. Princípio da vedação do retrocesso social. jul. 2012. Disponível em: < http://goo.gl/8ROAUv>. Acesso em: 13 mar. 2015.

SILVA, Gilda Olinto do Valle. Capital cultural, classe e gênero em Bourdieu. Revista Informare. Curitiba, PR, v. 1, n. 2, p. 24-36, jul./dez. 1995. Disponível em:

< http://goo.gl/nq4hCh>. Acesso em: 23 jan. 2014.

SOUZA, Celina. "Estado do Campo" da pesquisa em políticas públicas no Brasil. Revista Brasileira de Ciências Sociais, São Paulo, SP, v. 18, n. 51, p. 15-20, p. 15-20. 2003.

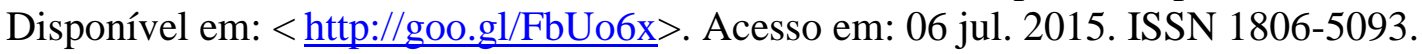

Como citar este documento:

CAUDURO, Maria Teresa; WERLE, Flavia Obino; CAUDURO, Maria Teresa. Prounistas que ingressam na pós-graduação. ETD - Educação Temática Digital, Campinas, SP, v. 17, n. 3, set./dez. 2015. ISSN 1676-2592. Disponível em: 〈http://periodicos.sbu.unicamp.br/ojs/index.php/etd/article/view/8638231〉. Acesso em: 15 dez. 2015. 